\title{
Military Surgery, Our Debt to Our Patients and Predecessors
}

\author{
Professor Charles G Rob, * \\ $M C, M D$, FRCS, FACS
}

We all remember patients who taught us valuable lessons. I will begin my lecture honouring Major General Philip Mitchiner by speaking about Company Sergeant Major Steadman of the First Parachute Battalion. On November 18, 1942, on the road from Bega to Mateur in Tunisia, two platoons of his Company and a group of engineers ambushed a patrol of three German armoured cars and three scout cars. He received a small wound of the anterior muscles of his thigh. He was driven to me in a Volkswagen scout car which had been captured in the ambush. I operated about 40 minutes after the incident. The wound was excised, some clothing and a small metallic foreign body removed. I felt that this was a good wound to close primarily, so I put in four skin sutures and thought we would have him back to duty in four or five days. At that time, we could not evacuate our patients to the rear. Next day his wound was red, swollen and inflamed. I took out the sutures and it was more than four weeks before he was fit for duty. I then remembered what Major General Philip Mitchiner and others had said at the beginning of World War II in 1939, "The surgeon is not yet born who does not think that he is the one who can close a gunshot wound primarily". I was very lucky and so was CSM Steadman. My over-confidence and poor surgical judgement could have caused a major problem. If we had established the usual line of evacuation, his leg wound, which had been sutured, would have become much worse and in those days before penicillin he would have probably developed a serious and perhaps fatal infection. I never closed another war wound primarily. A compensation was that CSM Steadman was awarded the Military Medal.

This problem recurs again and again at the beginning of every war and in every country. In December 1941 at Pearl Harbour, Lieutenant General Leonard Heaton, who was then a Major and Chief Surgeon of the Hospital at Schofield Barracks, laid down strict rules for the handling of the wounds. They were excised, left open and dusted with sulfanilamide powder. No case of gas gangrene occurred. At other hospitals on the island many wounds were closed and 12 patients developed gas gangrene.

*Professor of Surgery, Uniformed Services University of Health Sciences, F. Edward Herbert Sch. of Medicine, 4301 Jones Bridge Road, Bethesda, Maryland.
Major General Mitchiner died in 1952. Those of us who knew him well can tell innumerable stories illustrating his humour, his kindness and his eccentricities. He was wise enough not to own a car and $\overrightarrow{0}$ to rent one with a chauffeur whenever it was necessary. $\vec{\overrightarrow{ }}$ I believe this saved him time, money and trouble. He never had a problem parking, he often used trains or buses and frequently walked. This lecture was initiated 3 by his colleagues in the University of London O.T.C. and is now an established event, thanks to those now in $\vec{N}$ command of the Army Medical Services.

Another predecessor and colleague who taught mega great deal was Sir Alexander Fleming. He receive्gd every honour that you can imagine and he really enjoy: it. We all know that he discovered lysozyme in 1921 and penicillin in 1928, but it is often forgotten that he speQt over four years in World War I studying the place \&fo antiseptics in the management of war wounds. By eardi 1915 he and Sir Almroth Wright had determined that although antiseptics killed bacteria in a test tube, in $\overrightarrow{0}$ wound they killed the phagocytes and living cells but dof not kill enough of the bacteria to make a differences: They advocated the earliest possible removal of all de tissue, all dirt and foreign bodies and the application of sterile saline solution to the wound which was left open They believed that antiseptics such as iodine were $\frac{0}{\mathbb{Q}}$ harmful and should not be applied to war wounds. The standard practice in the early years of World War I was $\overrightarrow{\overrightarrow{0}}$ to apply strong antiseptics. Alexander Fleming and Almroth Wright taught that locally applied antiseptics could not reach the depths of a wound even after excision. They also caused pain. In general terms the wound management they advocated in 1915 was what we all practiced in World War II. I believe that Alexander Fleming was a true pioneer in many things $\overrightarrow{\mathbb{d}}$ and that this was one. Unfortunately Sir Almroth Wright, although correct, was much too abrasive and the ideas of Fleming and himself were not widely adopted 3 . during the early years of the 1914-1918 war.

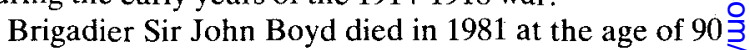
and was owed a lot by many of us. As a Wellcomeo trustee, he helped us at St. Mary's Hospital and voted on many occasions in favour of fellowships and grants음 for surgical research. In 1978 I went to live in Greenville, North Carolina where I found the largest manufacturing $\mathcal{N}$ facility operated by Burroughs Wellcome. It was $N$ interesting to discover that in this rural and somewhat 
isolated North Carolina community, the name of Brigadier Sir John Boyd was known and respected.

In 1940 and 1941, I was a member of the resident surgical staff at St. Thomas' Hospital. This was a very unusual time. Between 2.30am on September 9, 1940 and 9.00am on October 15, a period of five weeks, the hospital was hit by 11 large high explosive and many hundreds of incendiary bombs. One high explosive bomb had a delayed action fuse and exploded two hours after impact. In the Spring of 1941, two particularly heavy raids occurred on the hospital; the dates were April 16 and May 10. Damage was extensive from both high explosive and incendiary bombs. In my opinion, the damage on May 10, 1941 was nearly disastrous for St Thomas', but fortunately it was the last for three years. In July of 1944, the hospital was hit by two VI flying bombs; I was not present, being with the RAMC in Italy at that time.

The Blitz on London in the Autumn of 1940 and Winter and Spring of 1941 was a time of greatness. We felt that we were part of a just cause and in spite of the hardships, I think that Sir Winston Churchill was right when he stated that this was Britain's finest hour. It was exciting to be part of great events and London was full of people from all over the world. In my opinion, the civilian population behaved in a manner which may be equalled, but is unlikely to be excelled.

In the early Winter of 1941 , a very important American politician came one evening to St. Thomas' Hospital. He was a Republican and stated that he had been sent over by President Roosevelt to see if the British were going to hold. I never thought we were not, but he obviously needed convincing. He wished to see some civilian air raid casualties. He was brought over in an unofficial capacity by a junior member of the United States Embassy Staff. A moderate air raid was in progress and I took him to the emergency room where about 15 casualties, mostly with minor wounds were being treated. He was most impressed by the attitude of the patients. One young man had just lost his home; our visitor asked him what he was going to do about it. The man said, "Enlist tomorrow, I want to knock out that Hitler". I think this visit, although short, indicated very clearly to him that the British were going to hold and our Republican visitor reported this to both President Roosevelt and the Republican Party. About 18 years later Sir Winston was my patient. I told him about this unofficial visit and he said "I wish I had known". I said, "I couldn't have got near enough to tell you" and he said, "Yes, you are right".

On the night of November 23-24, 1942, Lt Col S J L Hill, C.O. of the First Battalion of the Parachute Regiment, and the Adjutant, Captain Miles Whitelock, were shot while taking the surrender of three tanks. Hill was shot in the left chest, Whitelock in the neck. Both were in shock but not severely unstable. At that time five others were wounded; three of these presented no problem and in due time received surgical treatment.
The other two had penetrating abdominal wounds with obvious severe shock. I did the triage. This indicated that both of these men were unlikely to survive an abdominal operation, particularly when blood transfusions were not available, except in small quantities from bleeding our own personnel. We treated the Adjutant first followed by the C.O.; this took about two hours. By this time, the two men with abdominal wounds had died. I still think perhaps they should have been treated first, but this taught me that a surgeon, if he is alone, must not commit himself to a long, complicated and probably useless operation when others are waiting for his services. The facts of triage can be traumatic for all concerned.

Sir Cameron Moffat, writing in 1976, summarized this very clearly. "There is a tendency to deal first with those who are most profoundly shocked and most seriously injured. But it should be remembered that the surgery of abdominal injury is often difficult, demanding and time consuming. Valuable time and energy may be wasted in an over ambitious attempt to save a mortally wounded patient while others, less seriously injured, may miss the optimum time for operation".

I will now comment upon a statement taken from the्ष ATLS Instructors Manual of 1984, sponsored by thẹ Committee on Trauma of the American College of Surgeons. "Many surgeons believe that the safes $\overrightarrow{\mathrm{P}}$ management of penetrating abdominal wounds is laparotomy". Experience from past wars and lessons learned from our patients leads me to question this. But I think we can all agree with another statement taker from the same manual. "All penetrating injuries of the abdomen should be evaluated by a surgeon".

During World War II, the incidence of possible unnecessary laparotomy in Europe and North Africá was quite high. Table 1 , taken from three published reports, indicates that of 5,126 laparotomies, in 848 or 16.5 per cent, no visceral lesion was found and that in 968 or 18.7 per cent, the wound involved the liver or kidney only. This means that at least 20 per cent of these laparotomies were unnecessary. In civilian life, this would be a matter for concern but would not be catastrophic because the mortality of an unnecessary laparotomy is not high, but in war, the patients frequently have multiple wounds, many of which are severe. The result is that the mortality of an unnecessary or negative laparotomy in a battle casualty can be as high as 20 per cent.

In a personal series ${ }^{2}$ of 172 patients with abdominal wounds treated between 1942 and 1945 no less than 85 had other wounds in addition to the abdominal wound, and in 21 of these the other wounds were severe: traumatic amputations, major muscle wounds with fractures, thoracic or cerebral wounds. Thirty-nine of these patients died and in seventeen of these - nearly half - the other wounds were a major cause of their death. The lesson in my opinion is obvious. In war multiple injuries change the whole picture and an 
unnecessary laparotomy will kill some patients. The answer is good triage and good diagnosis rather than routine laparotomy. Who will do this triage and make diagnoses?

As a surgeon, I like to operate. Should a surgeon take himself out of circulation by spending all day operating? Perhaps doing unnecessary laparotomies? The answer I think is that the experienced surgeon should be available for triage, leaving much of the actual operating to others. It is a mistake for this individual to take himself out of circulation by performing long complicated operations. In a sense he may be hiding from his true responsibilities by being in the operating room. In the past, this has not been put as strongly. I believe that in World War II many were guilty of this, including myself.

A lesson I learned from my patients in World War II was that the diagnosis of abdominal trauma is important. This should concentrate upon the need to explore the abdomen surgically. An experienced surgeon can avoid unnecessary abdominal explorations and save both lives and time for the care of other patients. To quote again from the ATLS Manual, "The primary factor in assessing and managing abdominal trauma is not the accurate diagnosis of specific type of injury, but rather the determination that an intra-abdominal injury exists and that operative intervention is not required". One particulary difficult situation occurs in that five per cent of patients with severe intra-abdominal bleeding who do not develop any specific findings. They are in shock and the shock continues with a falling hematocrit in spite of blood transfusions. Abdominal distention does not occur. For abdominal distention to be obvious ar associated paralytic ileus must occur. When there is ne associated ileus, a large amount of blood can be accommodated in the peritoneal cavity withoug detection.

Before we leave abdominal trauma, the question of? the management of liver and kidney wounds withoụ? laparotomy and of colonic wounds will be discussed. I World War II, I personally treated nine liver wound? and four kidney wounds without an abdomina exploration. They all survived. Some of my surgica? colleagues still discuss the primary closure of transverse्ల and left colon wounds. I expect that if war comes again尺्乛 the lesson will have to be re-learned that apart frones isolated wounds of the caecum and ascending colon, alt colonic wounds should be exteriorized if possible, or, if not possible, protected by a proximal colostomy. Ou $\vec{w}$ patients have already taught us this lesson. It is a shams to think that they will have to re-educate our successors@ T. G. Parks ${ }^{3}$ reporting in 1979 from Queen's Universit Hospital in Belfast where excellent hospital facilitie exist, confirms this.

The subject of triage leads to a discussion of the nee $\dot{\mathscr{C}}$ in warfare for well trained surgeons with a wide rangc్రి0 experience. What do we do with the specialist? The are many definitions of a surgical specialist, one is surgeon who is content to remain in ignorance $\overrightarrow{0} \overrightarrow{f_{T}}$

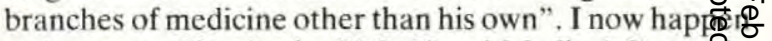
to have an office in the U.S. Naval Medical Center Bethesda. A problem is staffing the large hospitals o aircraft carriers, and there are a lot of them; they need a.

Table 1

Incidence of a Possibly Unnecessary Laparotomy

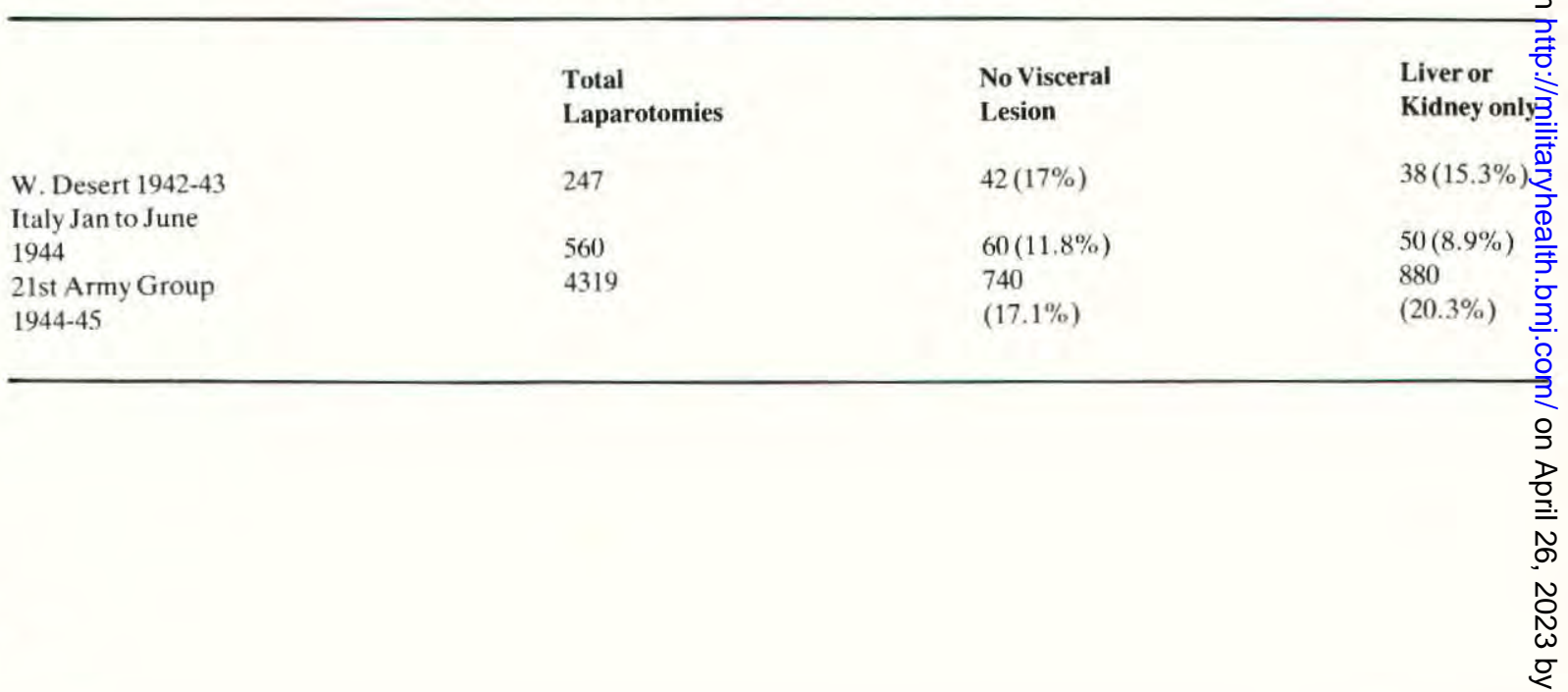


surgeon who can, in addition to undertaking routine surgery, treat fractures, burns, soft tissue wounds, abdominal wounds, thoracic wounds, et cetera. With our modern specialized training fewer and fewer men are able to do this. If we ever have another major conflict, this lack of capable men with wide training will be serious. Frankly, I think that apart from orthopaedic surgeons, many surgeons today cannot put on a good plaster cast, an essential for all surgeons in war when about 60 per cent of wounds will involve the extremities.

Of special interest is the Parachute Emergency Surgical Unit developed by the French. This unit differs from the Parachute Surgical Teams used by the British Airborne Divisions in World War II in that it is designed to operate only upon those patients who require almost instant surgery for respiratory obstruction, tension pneumothorax, severe hemorrhage which cannot be controlled by a tourniquet, et cetera. These few patients, if they improve, can then be evacuated with all other casualties to a surgical hospital.

It is probable that these units would be of special value in operations such as the United States assault on Grenada in 1983. I understand that the United States Marines have purchased two of these units.

The equipment consists of an operating table, a surgical light with a generator and suction, a tent, instruments and resuscitation fluids, including blood. The Israeli Army, using French equipment, had similar units mounted on trucks and these have been effective in treating this type of casualty.

It is nice to know that the flying ambulance introduced by Baron Larry into Napoleon's Army has now truely taken on wings and a French designed unit will serve the US Marines.

In America today the Morbidity and Mortality Conference held in all accredited hospitals, both military and civilian, is an important teaching session and an exercise in quality control. This is an excellent way of disseminating the knowledge learned from our patients. But it can be overdone. An example is the problem of operating for acute appendicitis and removing a normal appendix. This in many hospitals is reported as a complication at these meetings. We all know that it is reasonable to expect an incidence of normal appendectomy of 10 to 15 per cent ${ }^{4}$. But if each of these events is presented in such a way that the surgeon is excessively criticized by his colleagues and perhaps subjected to a malpractice legal action, it can be counter-productive. There is preliminary evidence in the U.S.A. that even though appendicitis is less common than it was a few years ago, the mortality of acute appendicitis is rising ${ }^{5,6}$. Perhaps this has been induced by these possibly misguided Morbidity and Mortality Conferences causing surgeons to delay operations. After all, diagnosing acute appendicitis and finding a normal appendix is not a complication; it is a mistake in diagnosis.

The development of the modern intensive care unit is the transfer to civilian life of a lesson learned in wartime. In my opinion the post-operative ward of World War II was the forerunner of the ICU of today. After 1945, it took about 15 years or more for Intensive Care Units to become established in civilian hospitals. Therefore, it appears that the field surgeons of World War II can think of themselves as the parents of the modern intensive care unit. In my opinion, this was a great step forward. Very sick patients became concentrated in one area with an equivalent concentration of house staff, highly skilled nurses and special equipment for patient monitoring and treatment. It appears that this has been both cost effective and a very good thing. In this respect, the civilian hospitals of today owe military surgeons a great debt.

A major reason for the good results obtained by the surgeons of the RAMC in World War II was the excellent blood transfusion service. This fine service saved many lives but occasionally a problem arose. The following is a quotation from the Medical Research Council published in $1951^{7}$. "Twenty-five days after

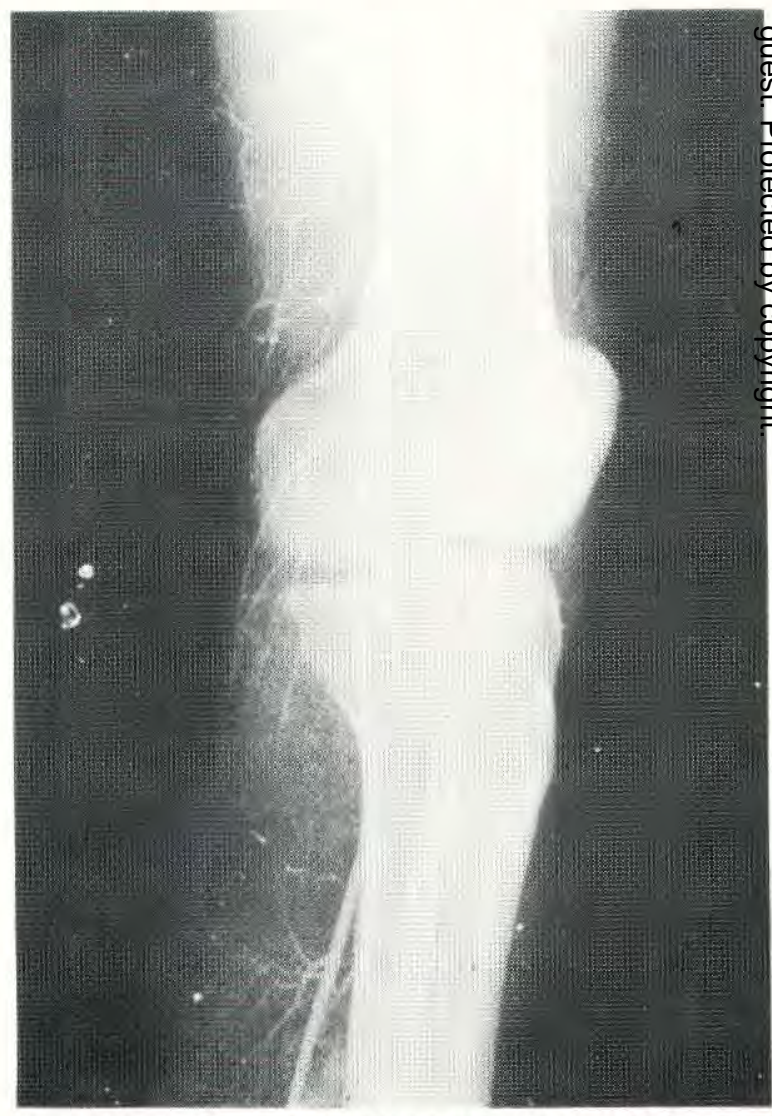

Fig 1. Arteriogram taken in 1944 at Trani, Italy. This is a post operative study after the repair of an arterio-venous fistula by $\mathrm{Lt}$ Col J. Mason Brown and myself. Some of the false sac was used for the repair. 
successful surgery for multiple gunshot wounds of the abdomen, he was given a transfusion of about $70 \mathrm{ml}$ of blood which proved to have been heavily infected with coliform bacilli and which produced a pronounced fall of blood pressure and anuria. B.P. 60/40. P. 160. T $105^{\circ} \mathrm{F}$. Blood urea $200 \mathrm{mgm}$. Recovery of the blood pressure and renal function followed further transfusion of plasma and fresh blood". I have special knowledge of this patient because he was my brother, John, then a Lieutenant in the Scots Guards. He subsequently had a distinguished career in the Foreign Service being High Commissioner in Singapore just before and after that country separated from Malaysia in 1965. In Singapore, he lived in Eden House and had a large staff, including seven gardeners. Those were the days!

As a vascular surgeon, I must record some lessons I have been taught by my patients and predecessors in this special field. In the Autumn of 1944, Lt Col James Mason Brown and I operated on a Jugoslav partisan with an arteriovenous fistula of the popliteal vessels (Fig 1). We repaired it with the return of strong ankle pulses. We showed the post operative arteriogram to Major General Mitchener at the RAMC Surgical Congress in Rome about three months later. He asked, "Did you use any of the false aneurysmal sac to make the repair? If you did, you will get an aneurysm later". He was right. In 1954, this man turned up at St Mary's, and you see from the arteriogram an aneurysm had formed (Fig 2). We replaced this with a vein graft. In effect, he had a two stage operation which was successful because his leg survived. Then, in 1953, Corporal Harold Alderoft came to our clinic at St Mary's with an enormous arteriovenous fistula between the right internal iliac vessels. This had been caused by a mortar bomb in 1945 . He was in congestive cardiac failure. The operation was extremely difficult, in fact almost impossible. Thirty years later we saw a U.S. Marine with a similar problem. The lessons learned from Harold Aldcroft were of great value. This time, using deep hypothermia, a cardiopulmonary bypass and total cardiac arrest, the fistula was quickly and successfully repaired by $\mathrm{Col}$ George J. Collins,

In conclusion I will quote from a statement made by that great surgeon and even greater speaker, Wilfred Trotter, "The human mind reacts to a new idea as the human body reacts to a foreign protein. It forms an antibody and tries to reject it". Major General Philip Mitchiner's mind was an exception; he welcomed new ideas and concepts, particularly those which came from young men.

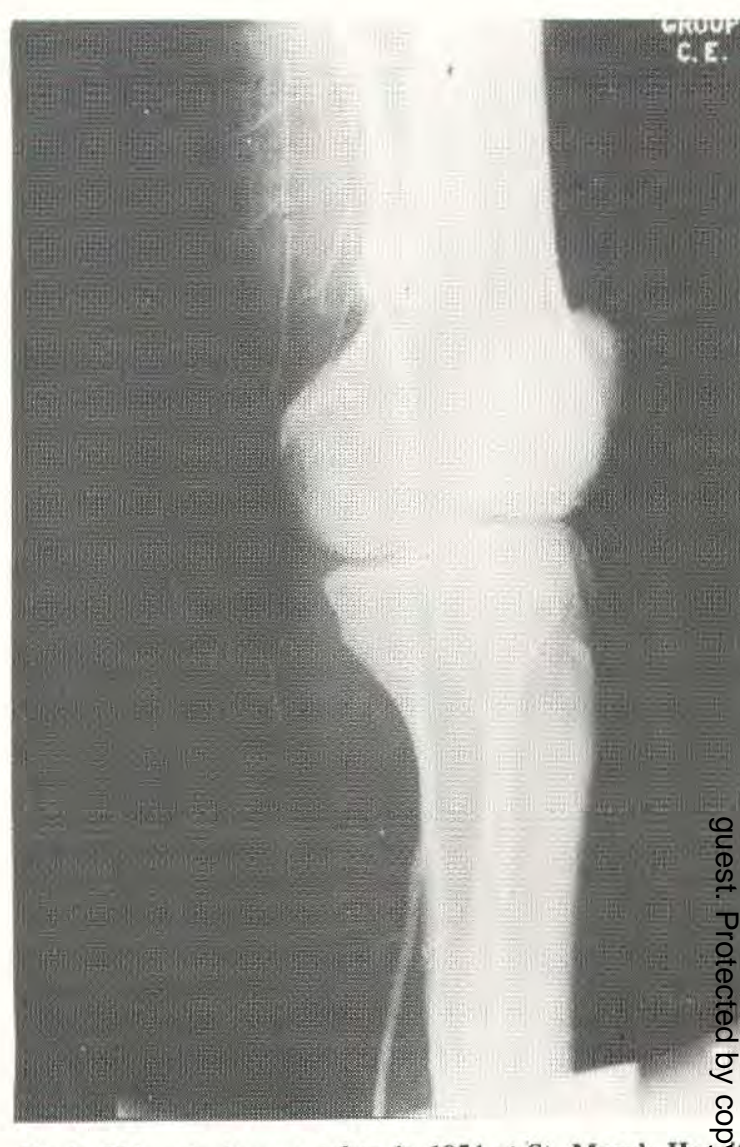

Fig 2. This arteriogram taken in 1954 at St. Mary's Hos shows that a false aneursym has formed in the patient shove Figure 1. A vein graft bypass was successful in maintaining ankle pulses.

\section{REFERENCES}

1 Fleming A. On the Bacteriology of Septic Woun Lancet $1915 ; 2.638-643$.

2 RoB C G. The Diagnosis of Abdominal Trauma Warfare, Surg Gynecol Obstet 1947; 85: 147-154.

3 PARks T G. Surgical Management of Gunshot Injuries the Large Intestine. JR Soc Med 1979; 72: 412-416.

4 SchwARTz S I. IN: "Principles of Surgery", 4th Ed. Ed Shires G T. Pub McGraw 1983.

5 Mittelpunkt A and NorA P F. Current Features in t\$⿸尸e Treatment of Acute Appedicitis. Surgery 1966; $\mathbb{6}$ : 971-975.

6 Lewis F R. et al. Appendicitis. Arch Surg 1975; 1 id: 677-684.

7 Grant R $T$ and Reeve E B. Observations on tige General Effects of Injury in War. Medical Researg్th Council Report 1951: 277: 176. 